\title{
Are lower levels of physical activity and self-rated fitness associated with higher levels of psychological distress in Croatian young adults? A cross-sectional study
}

\author{
Lovro Štefan ${ }^{\text {Corresp., }}{ }^{1}$, Goran Sporiš ${ }^{1}$, Tomislav Krističević ${ }^{2}$ \\ 1 Department of General and Applied Kinesiology, Faculty of Kinesiology, University of Zagreb, Croatia, Zagreb, Croatia \\ 2 Department of Sports Kinesiology, Faculty of Kinesiology, University of Zagreb, Croatia, Zagreb, Croatia \\ Corresponding Author: Lovro Štefan \\ Email address: lovro.stefan1510@gmail.com
}

\section{Background}

Although previous evidence has shown that physical activity and physical fitness lower the level of psychological distress, little is known of simultaneous associations between of physical activity and physical fitness and with psychological distress, especially in young adults. Therefore, the main purpose of the present study was to explore both separate and simultaneous association between physical activity and physical fitness with psychological distress.

Methods

Participants in this cross-sectional study were 2100 university students (1041 men and 1059 women) chosen from 8 faculties in the city of Zagreb. Physical activity, physical fitness and psychological distress were assessed using structured questionnaires. The associations were examined using logistic regression analysis.

Results

After adjusting for gender, body-mass index, self-rated health, material status, binge drinking, chronic disease/s and sleep quality, 'insufficient' physical activity (OR=2.60; 95\% Cl 1.92-3.52) and 'lower' levels of physical fitness (tertile 2; $\mathrm{OR}=1.94 ; 95 \% \mathrm{Cl} 1.25-3.01$ and tertile $1 ; \mathrm{OR}=2.59 ; 95 \% \mathrm{Cl} 1.65-4.08$ ) were remained associated with 'high' psychological distress. When physical activity and physical fitness were entered simultaneously into the model, 'insufficient' physical activity $(\mathrm{OR}=2.35 ; 95 \% \mathrm{Cl} 1.72-3.21)$ and 'lower' levels of physical fitness (tertile 2; $\mathrm{OR}=1.77 ; 95 \% \mathrm{Cl} 1.24-2.77$ and tertile $1 ; \mathrm{OR}=2.00 ; 95 \% \mathrm{Cl}$ 1.26-3.20) remained associated with 'high' psychological distress.

Conclusions Our study shows that both 'insufficient' physical activity and 'lower' levels of physical fitness are associated with 'high' psychological distress, even after adjusting for numerous covariates. Therefore, special policies aiming to increase the levels of physical activity and fitness are warranted. 
1

\section{Are lower levels of physical activity and self-rated fitness associated with higher levels of psychological distress in Croatian young adults? A cross- sectional study}

Running title: Physical activity and distress

Lovro Štefan ${ }^{1}$, Goran Sporiš² ${ }^{2}$ Tomislav Krističević ${ }^{3}$

${ }^{1}$ Faculty of Kinesiology, Department of General and Applied Kinesiology, University of Zagreb,

${ }^{2}$ Faculty of Kinesiology, Department of General and Applied Kinesiology, University of Zagreb, 10000 Zagreb, Croatia, e-mail: sporis.79@gmail.com

${ }^{3}$ Faculty of Kinesiology, Department of Sports Kinesiology, University of Zagreb, 10000

Zagreb, Croatia, e-mail: tomislav.kristicevic@kif.hr

Corresponding author: Lovro Štefan

Faculty of Kinesiology

University of Zagreb, Croatia,

Horvaćanski zavoj 15,

Tel: 0385-09891-77-060

E-mail: 1ovro.stefan1510@gmail.com 
30

31

32

33

\section{Abstract}

\section{Background}

Although previous evidence has shown that physical activity and physical fitness lower the level of psychological distress, little is known of simultaneous associations of physical activity and physical fitness with psychological distress, especially in young adults. Therefore, the main purpose of the present study was to explore both separate and simultaneous association between physical activity and physical fitness with psychological distress.

\section{Methods}

Participants in this cross-sectional study were 2100 university students (1041 men and 1059 women) chosen from 8 faculties in the city of Zagreb. Physical activity, physical fitness and psychological distress were assessed using structured questionnaires. The associations were examined using logistic regression analysis.

\section{Results}

After adjusting for gender, body-mass index, self-rated health, material status, binge drinking, chronic disease/s and sleep quality, 'insufficient' physical activity (OR=2.60; 95\% CI 1.92-3.52) and 'lower' levels of physical fitness (tertile 2; OR=1.94; 95\% CI 1.25-3.01 and tertile 1; $\mathrm{OR}=2.59 ; 95 \%$ CI 1.65-4.08) were remained associated with 'high' psychological distress. When physical activity and physical fitness were entered simultaneously into the model, 'insufficient' physical activity $(\mathrm{OR}=2.35 ; 95 \%$ CI 1.72-3.21) and 'lower' levels of physical fitness (tertile 2; $\mathrm{OR}=1.77$; 95\% CI 1.24-2.77 and tertile 1; $\mathrm{OR}=2.00 ; 95 \%$ CI 1.26-3.20) remained associated with 'high' psychological distress.

\section{Conclusions}

Our study shows that both 'insufficient' physical activity and 'lower' levels of physical fitness are associated with 'high' psychological distress, even after adjusting for numerous covariates. Therefore, special policies aiming to increase the levels of physical activity and fitness are warranted. 


\section{Introduction}

Mental health disorders have become one of the main public health problems worldwide, with special increasing prevalence among youth (Costello et al., 2003). Approximately 30\% of children and adolescents present mental disorders in the United States (Costello et al., 2003). In Croatia, the prevalence of mental disorders among youth is 15.7\% (Rudan et al., 2005), girls experienced high psychological distress more frequently in the last 30 days, compared with boys (33\% vs. 16\%) (Novak and Kawachi, 2015). In general, psychological distress is a term frequently used to describe the experience of unpleasant emotions and feelings that influence on everyday functioning (Perales, del Pozo-Cruz and del Pozo-Cruz, 2014) and has been consistently associated with cardiovascular (Mensah and Collins, 2015), metabolic (Newcomer, 2007) and musculoskeletal (Patten, Williams and Wang, 2006) diseases, cancer (Kisely, Crowe and Lawrence, 2013) and overall mortality (Walker, McGee and Druss, 2015).

Treatment for depression is antidepressant medication (Barbour, Hoffman and Blumenthal, 2013), which is expensive with potential side effects. Nevertheless, regular physical activity may serve as a protective factor against mental disorders. Physical activity is defined as "any bodily movement produced by skeletal muscles that results in energy expenditure and can be categorized into occupation, sports, conditioning, household, or other activities" (Caspersen, Powell and Christenson, 1985). The health benefits of physical activity on mental health have been well-documented (World Health Organization, 2010). Specifically, Larun et al. (2006) in their meta-analytical review showed, that vigorous physical activity had small effect in reducing anxiety or depression symptoms in youth. One meta-analysis showed that overall effects of physical activity on mental health were small, yet significant and indicated that physical activity led to improvements of mental health outcomes in children (Ahn and Fedewa, 2010). To determine causal direction, one longitudinal study showed that the number of hours spent in physical activity per week at age 15-16 was negatively associated with emotional symptoms in boys, yet no associations were found in girls (Sagatun et al., 2007). The same study also showed, that boys and girls who spent 5-7 hours of physical activity per week at the same age had the least mental difficulties reported after a three year of follow-up (Sagatun et al., 2007). While physical activity is related to the body movement, physical fitness represents "a set of attributes that people have or achieve" (Caspersen, Powell and Christenson, 1985). In general, physical 
88 fitness has two components: 1) health-related and skill-related, where each component has a set 89 of sub-components (Caspersen, Powell and Christenson, 1985). (Similar studies aiming to

90

91 92 93 explore the associations between physical fitness and psychological distress have also shown, that young adults with higher levels of cardio-respiratory, strength and flexibility fitness (Pouzelo-Carrascosa et al., 2017; Jeoung, Hong and Lee, 2013)have significantly lower levels of mental health disorders, compared to their peers with lower levels of fitness and higher levels of mental health disorders.

Previous studies have tried to explain the complexity and mutual processes of biological and psychological factors that physical activity has on mental health (Faulkner and Taylor, 2009). In terms of biological factors, physical activity has beneficial effects on neurotransmitters (monoamines, dopamine, endorphin), which play an important role in regulating stress and emotions and rewarding motivation (Paluska and Schwenk, 2000). Psychological factors include self-esteem, self-efficacy and distraction, and physical activity/fitness play an important role in increasing such perceptions (Ekeland et al., 2004).

Thus, according to the literature, it is well-established, that both physical activity and physical fitness have beneficial role on mental health. However, little is known about the relationship these two potential factors with mental health in young adults. Young adulthood is characterized by the onset of which mental health problems start to occur (Kessler et al., 2005). On the other hand, it has been reported that $40 \%$ of young adults from United States do not meet the recommendations of National physical activity guidelines (150 min of moderate or $75 \mathrm{~min}$ of vigorous physical activity weekly) leading to excessive weight gain (Malhotra et al., 2013) and other diseases (Warburton, Nicole and Bredin, 2006).

Since young adults represent a risk group for higher levels of mental health disorders and lower levels of physical activity, it is necessary to explore these associations. Therefore, the main purpose of the present study was to explore both separate and simultaneous associations of physical activity and physical fitness with psychological distress in a large sample of young adults. 


\section{Participants}

118 This study was conducted among university students in Zagreb, the capital city of Croatia with 119 approximately 1000000 citizens. The University of Zagreb is composed of 33 faculties 120 (departments) and between 65000 to 70000 students attend the University every year. A random 121 sampling approach was used to select faculties. At the first stage, we randomly selected 8 out of 12233 faculties. The randomization was done with replacement, where each faculty had unique 123 number and was drawn from the box. At the second stage, we contacted teachers from each 124 faculty to help us organize the sampling procedure. A recruitment announcement was sent via 125 emails and e-newsletter to the teachers with a request to pass the study information to students. 126 All 8 faculties agreed to take part in the study, representing 2320 students enrolled in the 2017 127 academic year. Of these, 2100 students (1041 men and 1059 women, aged 18-24 years) provided 128 full data $(90.5 \%)$ and were enrolled in further analysis. Students came from a variety of social 129 (psychology, political sciences, economy and business), technical (computing, information 130 technologies, electrical engineering, civil engineering, mechanical engineering, graphics arts and 131 naval architecture) and health-related (medical doctors, physiotherapists, nurses) sciences. 132 Before the main analysis, we examined the differences between the participants and non133 participants in terms of gender, age, body-mass index, self-rated health and psychological 134 distress. No significant differences were observed and no potential bias was made $(\mathrm{p}=0.21-0.74)$. 135 All the analysis and procedures were anonymous and in accordance with the Declaration of 136 Helsinki and approved by the Institutional Review Board of the Faculty of Kinesiology (Ethics 137 code: 16/2017). Also, all participants gave their written informed consent for participation in the 138 study.

\section{Outcome variable}

140 Psychological distress was assessed by using Kessler's 6-item questionnaire: (1) "How often 141 during the past 30 days did you feel nervous?", (2) "How often during the past 30 days did you 142 feel hopeless?", (3) "How often during the past 30 days did you feel restless or fidgety?", (4) 143 "How often during the past 30 days did you feel so depressed that nothing could cheer you up?", 144 (5) "How often during the past 30 days did you feel that everything was an effort?" and (6) 145 "How often during the past 30 days did you feel worthless?" (Kessler et al., 2003). Each question 146 is scored from 0 (none of the time) to 4 (all of the time). Scores of each question are summed up 
147 ranging from 0-24, with lower score indicating lower level of psychological distress. Kessler et

148 al. (2003) showed, that responses $<13$ points vs. $\geq 13$ points discriminated participants without 149 and with psychological distress.

150

151

152

153

154

155

156

157

158

159

160

161

162

163

164

165

166

167

168

169

170

171

172

173

174

Physical activity

To assess physical activity in the last 7 days, we used International Physical Activity questionnaire, a reliable and valid instrument designed to measure physical activity in respondents between ages 18-65 (Craig et al., 2003). Specifically, this measure assesses the types of intensity of physical activity during the day to estimate total physical activity measured in metabolic equivalent units-min/week. We created a dichotomized variable, where 'sufficiently active' participants participated in at least (1) $150 \mathrm{~min} /$ week in moderate physical activity or (2) 75 min of vigorous physical activity or (3) an equivalent combination of both compared with 'insufficiently active' participants (World Health Organization, 2010).

Physical fitness

Self-rated physical fitness was assessed by using one-time question:"How would you rate your physical fitness?" ranging from 1 (very poor) to 10 (excellent) (Plante, LeCaptain \& McLain, 2000). This measure has previously been correlated with measures of objective physical fitness and perceived well-being (Plante, Lantis \& Checa, 1998) and used in similar studies (Gerber et al., 2010).

\section{Covariates}

Previous studies have shown, that body-mass index, socioeconomic status, alcohol consumption, having a long-term health condition, self-rated health and sleep quality are known or suspected to influence psychological distress and we included them as covariates in the analysis (Novak and Kawachi, 2015; Perales, del Pozo-Cruz and del Pozo-Cruz, 2014; Sagatun et al., 2007). Participants self-reported their height in meters (m) and weight in kilograms (kg), from which body-mass index $\left(\mathrm{kg} / \mathrm{m}^{2}\right)$ was calculated. Before the study began, we had chosen 35 men and 40 women to validate self-reported height and weight with the objective measure taken by trained survey staff. Pearson's coefficient of correlation showed excellent relationship between two measures in men $(r=0.96)$ and women $(r=0.97)$. For the purpose of this study, we divided body- 
175 mass index score into two categories: (1) normal $\left(<25 \mathrm{~kg} / \mathrm{m}^{2}\right)$ vs. (2) overweight/obesity $(\geq 25$

$176 \mathrm{~kg} / \mathrm{m}^{2}$ ). Although not appropriate as a clinical tool, self-reported BMI serves as a valid tool for

177 epidemiological surveys, especially in young adults (Meyer et al., 2012). Self-rated health was

178 assessed using one-item question:"How would you rate your health?“. Answers were arranged

179 along a Likert-type scale as follows: (1) very poor, (2) poor, (3) fair, (4) good and (5) excellent.

180 For the purpose of this study, we dichotomized the outcome variable into 'good' (fair, good and

181 excellent) vs. 'poor' (very poor and poor) self-rated health (Štefan et al., 2017). Material status

182 was assessed by one question:"How would you perceive your material status, based on your 183 parents' occupation?“. Responses were: (1) low, (2) medium and (3) high. We created two 184 categories as follows: (1) low and (2) medium/high. Binge alcohol consumption was assessed by 185 one question:“ How often do you have (for men) 5 or more and (for women) 4 or more drinks on 186 one occasion?“ (Peltzer and Pengpid, 2016). Those who had (for men) 5 or more and (for 187 women) 4 or more drinks on one occasion were categorized as "Yes", compared to "No" group 188 who had less drinks on one occasion. The presence or absence of a chronic disease was asked by 189 one-item question:"Have you ever been told by a doctor, that you suffer from any kind of 190 chronic disease?" with "Yes" and "No" answers. To assess sleep quality, we asked about current 191 self-perceived state of sleep quality:“How would you perceive your sleep quality?“. Answers 192 193 were arranged across a four-item scale as follows: (1) very good, (2) good, (3) poor and (4) very poor. Very good and good collapsed into 'good' and poor and very poor into 'poor' sleep quality.

Data analysis

196

Basic descriptive statistics of the study participants are presented as frequencies (N) and 197 percentages (\%). Differences between categorical variables between 'low' and 'high' psychological distress were analyzed using Chi-square test. To explore the associations between physical activity and physical fitness with psychological distress, we performed a set of logistic regression analyses. We calculated odd ratios (ORs) with 95\% confidence intervals (95\% CIs). 'High' psychological distress was the main outcome of the present study. First, we explored the association between 'insufficient' physical activity and 'high' psychological distress in model 1. Second, we explored the association between 'low' physical fitness and 'high' psychological distress. Since physical fitness was assessed by a ten-item scale, we calculated median and 
205 interquartile range ( $25^{\text {th }}$ and $75^{\text {th }}$ percentile range), in order to categorize participants into three

206 groups (tertiles): (1) $<25^{\text {th }}$ percentile as 'low', (2) $25^{\text {th }}-75^{\text {th }}$ percentiles as 'medium' and (3) $>75^{\text {th }}$

207 percentile as 'high' physical fitness. Finally, we entered both physical activity and physical

208 fitness simultaneously into the model (model 3). Significance was set up at $\alpha \leq 0.05$ and it was

209 one sided (1-sided). All the analysis were performed in Statistical Package for Social Sciences

210 Software, ver. 22 (IBM Corp., Armonk, NY, USA).

211

212

\section{Results}

213

214

215

216

217

218

219

220

221

222

223

224

225

226

227

228

229

230

231

232

233

Basic descriptive statistics of the study participants are presented in table 1 . The prevalence of 'high' psychological distress was $10.6 \%$, while $22.6 \%$ and $28.2 \%$ of the study participants were 'insufficiently' active and were in the 'lowest' physical fitness group. We found that higher percentage of 'insufficiently' active participants and those with 'lower' levels of physical fitness reported having 'high' psychological distress in the last 30 days. Also, higher percentage of women, those participants who reported having poor self-rated health, low material status, binge drinking, having a chronic disease and poor/very poor sleep had 'high' psychological distress in the last 30 days.

The associations between physical activity, physical fitness and psychological distress are presented in table 2. In model 1, 'insufficient' physical activity (OR=2.60; 95\% CI 1.92-3.52) was associated with 'high' psychological distress. In model 2, those participants in lower tertiles (tertile 2; $\mathrm{OR}=1.94 ; 95 \% \mathrm{CI} 1.25-3.01$ and tertile $1 ; \mathrm{OR}=2.59 ; 95 \% \mathrm{CI}$ 1.65-4.08) were more likely to experience 'high' psychological distress. Finally, when both physical activity and physical fitness were entered simultaneously into the model (model 3), OR for 'insufficient' physical activity $(\mathrm{OR}=2.35$; 95\% CI 1.72-3.21) and for 'lower' levels of physical fitness (tertile 2; $\mathrm{OR}=1.77 ; 95 \%$ CI 1.14-2.77 and tertile 1; OR=2.00;95\% CI 1.26-3.20) decreased, but remained associated with 'high' psychological distress. All three models were adjusted for gender, body-mass index, self-rated health, material status, binge drinking, chronic disease/s and sleep quality. The association between physical fitness and physical activity was moderate $(r=0.33, \mathrm{p}<0.001)$ and variance inflation factors test $(\mathrm{VIF})$ showed no multicollinearity (1.00 to $1.10)$. 


\section{Discussion}

235 The main purpose of the present study was to explore both separate and simultaneous 236 associations between physical activity and physical fitness and psychological distress in a large 237 sample of young adults. Both 'insufficient' physical activity and 'lower' levels of physical 238 fitness were associated with 'high' psychological distress after adjusting for gender, body-mass 239 index, self-rated health, material status, binge drinking, chronic disease/s and sleep quality.

240 Our results are in line with previous studies aiming to explore the associations between physical 241 activity/fitness and mental health (Sagatun et al., 2007; World Health Organization, 2010; Larun 242 et al., 2006; Pozuelo-Carrascosa et al., 2017; Jeoung, Hong and Lee, 2013). Specifically, Sagatun 243 et al. (2007), in their three-year longitudinal study showed, that weekly hours of physical activity 244 were negatively associated with emotional symptoms or peer problems only in boys, but not in 245 girls. As mentioned before, mental health is a complex state comprised of behavioral, 246 psychological and social components (Paluska and Schwenk, 2000; Ekeland et al., 2004;

247 Bandura, 1977). A few previous studies have shown, that participants, who are engaged in 248 regular physical activity displays much less inhibition in social behavior (Kirkcaldy, Shephard 249 and Siefen, 2002) and scored lower on psychological discomfort captured by loneliness, 250 hopelessness and shyness (Page and Tucker, 1994) compared to their physically inactive peers. 251 In addition to physical activity, studies aiming to explore the associations between physical 252 fitness and mental health disorders have shown that higher levels of cardio-respiratory, strength 253 and flexibility fitness are significantly associated with decreased mental health disorders, 254 compared to participants with lower levels of physical fitness (Pouzelo-Carrascosa et al., 2017; 255 Jeoung, Hong and Lee, 2013). Our results confirmed strong negative association between self256 perceived physical fitness and psychological distress, that is, 'lower' levels of physical fitness were associated with 'high' psychological distress.

258 The mechanism underlying the association between physical activity/fitness and mental health is not clearly understood (Blake, 2012). Previous meta-analytical reviews have shown small clinical effect that physical activity has on mental health (Larun et al., 2006; Ahn and Fedewa, 2010; Rimer et al., 2012). Although small, positive benefits of physical activity on health outcomes have been well-documented (Warburton, Nicole and Bredin, 2006). In terms of mental 
264 increased levels of motivation and positive emotions and reducing stress and pain (Paluska and 265 Schwenk, 2000; Ekeland et al., 2004; Bandura, 1977). Our results also showed that among 266 numerous factors we adjusted for, the strongest association was between 'very poor/poor' sleep 267 quality and 'high' psychological distress, which is similar to other studies (Feng et al., 2014). 268 Such associations between sleep quality and psychological distress could be mediated by 269 physical activity which regulates temperature following exercise and the onset of sleep declines 270 through vasodilatation of peripheral heat dissipation (Driver and Taylor, 2000). In that way, by 271 affecting on sleep quality, physical activity decreases psychological distress and improves 272 behavioral and emotional regulations.

273 Our study has some limitations. First, we used a cross-sectional design, in order to determine the associations between physical activity and physical fitness with psychological distress. To determine the causality, Reichenheim and Coutinho (2010) reported that the main outcome of the study should be frequent and might be different among subjects, due to a dynamic population. Second, we used subjective measures to assess psychological distress, physical activity, physical fitness and other covariates. However, self-reported measures are largely used in epidemiological studies. But, due to a better precision, future studies should use direct measurement method (motor and functional fitness tests) over a longer period of time, in order to track and establish causal direction of the association between physical activity/fitness and psychological distress.

\section{Conclusions}

284

Our results show strong associations between 'insufficient' physical activity and 'lower' levels of physical fitness with 'high' psychological distress in a large sample of young adults. Findings of this study should be taken into account, when establishing and implementing special strategies and policies that leverage higher participation in physical activity in order to decrease 'high' psychological distress. 
292

293 294

295

296

297

298

299

300

301

302

303

304

305

306

307

308

309

310

311

312

313

314

315

316

317

318

319

320

\section{Acknowledgments:}

We would like to thank teachers and students for their enthusiastic participation in the study.

\section{References}

1. Ahn S, Fedewa AL. 2010. A meta-analysis of the relationship between children's physical activity and mental health. Journal of Pediatric Psychology 36:385-397.

2. Bandura A. 1977. Self-efficacy: Toward a unifying theory of behavioural change. Psychological Review 84:191-215.

3. Blake H. Physical activity and exercise in the treatment of depression. 2012. Frontiers in Psychiatry 3:106.

4. Caspersen CJ, Powell KE, Christenson GM. 1985. Physical activity, exercise, and physical fitness: definitions and distinctions for health-related research. Public Health Reports 100:126-131.

5. Costello EJ, Mustillo S, Erkanli A, Keeler G, Angold A. 2003. Prevalence and development of psychiatric disorders in childhood and adolescence. Archives of General Psychiatry 60:837-844.

6. Craig CL, Marshall AL, Sjöström M, Bauman AE, Booth ML, Ainsworth BE, Pratt M, Ekelund U, Yngve A, Sallis JF, Oja P. 2003. International physical activity questionnaire: 12-country reliability and validity. Medicine and Science in Sports and Exercise 35:13811395.

7. Driver HS, Taylor SR. 2000. Exercise and sleep. Sleep Medicine Reviews 4:387-402.

8. Ekeland E, Heian F, Hagen KB, Abbott J, Nordheim L. 2004. Exercise to improve selfesteem in children and young people. Cochrane Database of Systematic Reviews 1:CD003683.

9. Faulkner G, Taylor A. 2009. Promoting physical activity for mental health: A complex intervention? Mental Health and Physical Activity 1:1-3.

10. Feng Q, Zhang Q, Du Y, Ye Y, He Q. 2014. Associations of physical activity, screen time with depression, anxiety and sleep quality among Chinese college freshmen. PLoS ONE 9:e100914. 
321

322

323

324

325

326

327

328

329

330

331

332

333

334

335

336

337

338

339

340

341

342

343

344

345

346

347

348

349

350

351

11. Gerber M, Brand S, Holsboer-Trachsler E, Puhse U. 2010. Fitness and exercise as correlates of sleep complaints: is it all in our minds? Medicine and Science in Sports and Exercise 42:893-901.

12. Jeoung BJ, Hong M-S, Lee YC. 2013. The relationship between mental health and health-related physical fitness of university students. Journal of Exercise Rehabilitation 9:544-548.

13. Kessler RC, Barker PR, Colpe LJ, Epstein JF, Gfroerer JC, Hiripi E, Howes MJ, Normand SL, Manderscheid RW, Walters EE, Zaslavsky AM. 2003. Screening for serious mental illness in the general population. Archives of general psychiatry 60:184-189.

14. Kessler RC, Berglund P, Demler O, Jin R, Merikangas KR, Walters EE. 2005. Lifetime prevalence and age-of-onset distributions of DSM-IV disorders in the National Comorbidity Survey Replication. Archives of general psychiatry 62:593-602.

15. Kirkcaldy BD, Shephard R, Siefen G. 2002. The relationship between physical activity and self-image and problem behavior among adolescents. Social Psychiatry and Psychiatric Epidemiology 37:544-550.

16. Kisely S, Crowe E, Lawrence D. 2013. Cancer-related mortality in people with mental illness. JAMA psychiatry 70:209-217.

17. Larun L, Nordheim LV, Ekeland E, Hagen KB, Heian F. 2006. Exercise in prevention and treatment of anxiety and depression among children and young people. Cochrane Database of Systematic Reviews 3:1-47.

18. Malhotra R, Ostbye T, Riley CM, Finkelstein E. 2013. Young adult weight trajectories through midlife by body mass category. Obesity 21:1923-1934.

19. Mensah GA, Collins PY. 2015. Understanding mental health for the prevention and control of cardiovascular diseases. Global heart 10:221-224.

20. Meyer KA, Wall MM, Larson NI, Laska MN, Neumark-Sztainer D. 2012. Sleep duration and BMI in a sample of young adults. Obesity (Silver Spring) 20:1279-1287.

21. Newcomer JW. 2007. Metabolic syndrome and mental illness. The American journal of managed care. 13:170-177.

22. Novak D, Kawacki I. 2015. Influence of different domains of social capital on psychological distress among Croatian high school students. International Journal of Mental Health Systems 9:18. 
352

353

354

355

356

357

358

359

360

361

362

363

364

365

366

367

368

369

370

371

372

373

374

375

376

377

378

379

380

381

382

23. Page RM, Tucker LA. 1994. Psychosocial discomfort and exercise frequency: an epidemiological study of adolescents. Adolescence 29:183-191.

24. Paluska SA, Schwenk TL. Physical activity and mental health. 2000. Current concepts. Sports Medicine 29:167-180.

25. Patten SB, Williams JV, Wang J. 2006. Mental disorders in a population sample with musculoskeletal disorders. BMC Musculoskeletal Disorders 7:37.

26. Peltzer K, Pengpid S. 2016. Sleep duration and health correlates among university students in 26 countries. Psychology, health \& medicine 21:208-220.

27. Perales F, del Pozo-Cruz J, del Pozo-Cruz B. 2014. Impact of physical activity on psychological distress: a prospective analysis of an Australian national sample. American Journal of Public Health 104:91-97.

28. Plante TG, Coscarelli L, Caputo D, Oppezzo M. 2000. Perceived fitness predicts daily coping better than physical activity. International Journal of Stress Management 7:182192.

29. Plante TG, Lantis A, Checa G. 1998. The influence of perceived versus aerobic fitness on psychological health and physiological stress responsitivity. International Journal of Stress Management, 5:141-156.

30. Pozuelo-Carrascosa DP, Martínez-Vizcaíno V, Sánchez-López M, Bartolomé-Gutierréz R, Rodríguez-Martín B, Notario-Pacheco B. 2017. Resilience as a mediator between cardiorespiratory fitness and mental health-related quality of life: A cross-sectional study. Nursing \& health sciences 19:316-321.

31. Rimer J, Dwan K, Lawlor DA, Greig CA, McMurdo M, Morley W, Mead GE. 2012. Exercise for depression. Cochrane Database of Systematic Reviews 7:CD004366.

32. Rudan V, Begovac I, Szirovicza L, Filipovic O, Skocic M. 2005. The child behavior checklist, teacher report form and youth self report problem scales in a normative sample of Croatian children and adolescents aged 7-18. Collegium Antropologicum 29:17-26.

33. Sagatun A, Søgaard AJ, Bjertness E, Selmer R, Heyerdahl S. 2007. The association between weekly hours of physical activity and mental health: A three-year follow-up study of 15-16-year-old students in the city of Oslo, Norway. BMC Public Health 7:155.

34. Štefan L, Juranko D, Prosoli R, Barić R, Sporiš, G. 2017. Self-reported sleep duration and self-rated health in young adults. Journal of Clinical Sleep Medicine 13:899-904. 
383

384

385

386

387

388

389

390

391

392

393

35. Walker ER, McGee RE, Druss BG. 2015. Mortality in mental disorders and global disease burden implications: A systematic review and meta-analysis. JAMA psychiatry. 72:334-341.

36. Warburton DER, Nicol CW, Bredin SSD. 2006. Health benefits of physical activity: the evidence. CMAJ : Canadian Medical Association Journal 174:801-809.

37. World Health Organization. 2010. Global recommendations on physical activity for health. Geneva, Switzerland: WHO Press. 


\section{Table 1 (on next page)}

Basic descriptive statistics of the study participants, Croatia (2017)

*Chi-square test 
Basic descriptive statistics of the study participants, Croatia (2017)

\begin{tabular}{|c|c|c|c|c|}
\hline Study variables & $\begin{array}{c}\text { Total sample } \\
(\mathrm{N}=\mathbf{2 1 0 0})\end{array}$ & $\begin{array}{l}\text { Low psychological } \\
\text { distress }(\mathrm{N}=1878)\end{array}$ & $\begin{array}{c}\text { High psychological } \\
\text { distress }(\mathrm{N}=222)\end{array}$ & $p$-value* \\
\hline & $\mathrm{N}(\%)$ & $\mathrm{N}(\%)$ & $\mathrm{N}(\%)$ & \\
\hline \multicolumn{5}{|l|}{ Physical activity } \\
\hline Sufficient & $1626(77.4)$ & $1502(92.4)$ & $124(7.6)$ & \\
\hline Insufficient & $474(22.6)$ & $376(20.0)$ & $98(80.0)$ & $<0.001$ \\
\hline \multicolumn{5}{|l|}{ Physical fitness } \\
\hline Tertile 3 (highest) & $601(28.6)$ & $572(95.2)$ & $29(4.8)$ & \\
\hline Tertile 2 & $907(43.2)$ & $809(90.2)$ & $98(10.8)$ & \\
\hline Tertile 1 (lowest) & $592(28.2)$ & $497(84.0)$ & $95(16.0)$ & $<0.001$ \\
\hline \multicolumn{5}{|l|}{ Gender } \\
\hline Men & $1041(49.6)$ & $975(93.7)$ & $66(6.3)$ & \\
\hline Women & $1059(50.4)$ & $903(85.3)$ & $156(14.7)$ & $<0.001$ \\
\hline \multicolumn{5}{|l|}{ Body-mass index } \\
\hline Normal & $1765(84.0)$ & $1577(89.3)$ & $188(10.7)$ & \\
\hline Overweight/obesity & $335(16.0)$ & $301(89.9)$ & $34(10.1)$ & 0.847 \\
\hline \multicolumn{5}{|l|}{ Self-rated health } \\
\hline Good & $1935(92.1)$ & $1750(90.4)$ & $185(9.6)$ & \\
\hline Poor & $165(7.9)$ & $120(77.6)$ & $37(22.4)$ & $<0.001$ \\
\hline \multicolumn{5}{|l|}{ Material status } \\
\hline Middle/high & $2048(97.5)$ & $1839(89.8)$ & $209(10.2)$ & \\
\hline Low & $52(2.5)$ & $39(75.0)$ & $13(25.0)$ & $\mathbf{0 . 0 0 2}$ \\
\hline \multicolumn{5}{|l|}{ Binge drinking } \\
\hline No & $1530(72.9)$ & $1391(90.9)$ & $139(9.1)$ & \\
\hline Yes & $570(27.1)$ & $487(85.4)$ & $83(14.6)$ & $<0.001$ \\
\hline \multicolumn{5}{|l|}{ Chronic disease/s } \\
\hline No & $1905(90.7)$ & $1721(90.3)$ & $184(9.7)$ & \\
\hline Yes & $195(9.3)$ & $157(80.5)$ & $38(19.5)$ & $<0.001$ \\
\hline \multicolumn{5}{|l|}{ Sleep quality } \\
\hline Very good/good & $687(32.7)$ & $658(95.8)$ & $29(4.2)$ & \\
\hline Poor/very poor & $1413(67.3)$ & $1220(86.3)$ & $192(13.7)$ & $<\mathbf{0 . 0 0 1}$ \\
\hline
\end{tabular}




\section{Table 2 (on next page)}

Odd ratios for high psychological distress of the study participants, Croatia (2017)

Model 1: examine the associations of physical activity with psychological distress adjusted for gender, body-mass index, self-rated health, material status, binge drinking, chronic disease/s and sleep quality. Model 2: examine the associations of physical fitness with psychological distress adjusted for gender, body-mass index, self-rated health, material status, binge drinking, chronic disease/s and sleep quality. Model 3: examine the associations of physical activity and physical fitness entered simultaneously into the model with psychological distress adjusted for gender, body-mass index, self-rated health, material status, binge drinking, chronic disease/s and sleep quality. ${ }^{* * *} p<0.01 ; * * p<0.01 ; * p<0.05$ 


\begin{tabular}{|c|c|c|c|}
\hline Study variables & $\begin{array}{l}\text { Physical activity and } \\
\text { psychological distress }\end{array}$ & $\begin{array}{l}\text { Physical fitness and } \\
\text { psychological distress }\end{array}$ & $\begin{array}{l}\text { Physical activity and } \\
\text { physical fitness with } \\
\text { psychological distress }\end{array}$ \\
\hline & OR $(95 \%$ CI $)$ & OR $(95 \%$ CI $)$ & OR $(95 \% \mathrm{CI})$ \\
\hline \multicolumn{4}{|l|}{ Physical activity } \\
\hline Sufficient & 1.00 & & 1.00 \\
\hline Insufficient & $2.60(1.92-3.52)^{* * *}$ & & $2.35(1.72-3.21)^{* * *}$ \\
\hline \multicolumn{4}{|l|}{ Physical fitness } \\
\hline Tertile 3 (highest) & & 1.00 & 1.00 \\
\hline Tertile 2 & & $1.94(1.25-3.01)^{* *}$ & $1.77(1.14-2.77)^{*}$ \\
\hline Tertile 1 (lowest) & & $2.59(1.65-4.08)^{* * *}$ & $2.00(1.26-3.20)^{* *}$ \\
\hline \multicolumn{4}{|l|}{ Gender } \\
\hline Men & 1.00 & 1.00 & 1.00 \\
\hline Women & $2.18(1.57-3.02)^{* * *}$ & $2.17(1.57-3.01)^{* * *}$ & $2.00(1.44-2.78)^{* * *}$ \\
\hline \multicolumn{4}{|l|}{ Body-mass index } \\
\hline Normal & 1.00 & 1.00 & 1.00 \\
\hline Overweight/obesity & $1.09(0.71-1.67)$ & $1.01(0.66-1.55)$ & $1.02(0.66-1.57)$ \\
\hline \multicolumn{4}{|l|}{ Self-rated health } \\
\hline Good & 1.00 & 1.00 & 1.00 \\
\hline Poor & $2.13(1.38-3.30)^{* * *}$ & $2.03(1.31-3.12)^{* * *}$ & $2.04(1.31-3.16)^{* * *}$ \\
\hline \multicolumn{4}{|l|}{ Material status } \\
\hline Middle/high & 1.00 & 1.00 & 1.00 \\
\hline Low & $2.32(1.14-4.74)^{*}$ & $2.12(1.04-4.33)^{*}$ & $2.22(1.08-4.53)^{*}$ \\
\hline \multicolumn{4}{|l|}{ Binge drinking } \\
\hline No & 1.00 & 1.00 & 1.00 \\
\hline Yes & $1.71(1.26-2.33)^{* * *}$ & $1.76(1.30-2.38)^{* * *}$ & $1.75(1.28-2.93)^{* *}$ \\
\hline \multicolumn{4}{|l|}{ Chronic disease/s } \\
\hline No & 1.00 & 1.00 & 1.00 \\
\hline Yes & $1.91(1.26-2.89)^{* * *}$ & $1.96(1.30-2.95)^{* * *}$ & $1.94(1.28-2.93)^{* *}$ \\
\hline \multicolumn{4}{|l|}{ Sleep quality } \\
\hline Very good/good & 1.00 & 1.00 & 1.00 \\
\hline Poor/very poor & $3.44(2.28-5.19) * * *$ & $3.34(2.22-5.04) * * *$ & $3.29(2.18-4.98)^{* * *}$ \\
\hline
\end{tabular}

Model 1: examine the associations of physical activity with psychological distress adjusted for gender, body-mass index, self-rated health, material status, binge drinking, chronic disease/s and sleep quality.

4 Model 2: examine the associations of physical fitness with psychological distress adjusted for gender, body-mass 5 index, self-rated health, material status, binge drinking, chronic disease/s and sleep quality.

6 Model 3: examine the associations of physical activity and physical fitness entered simultaneously into the model 7 with psychological distress adjusted for gender, body-mass index, self-rated health, material status, binge drinking,

8 chronic disease/s and sleep quality.

$9 \quad * * * \mathrm{p}<0.01 ; * * \mathrm{p}<0.01 ;{ }^{*} \mathrm{p}<0.05$ 